\title{
Functional Roles of Electrogenic Sodium Bicarbonate Cotransporter NBCe1 in Ocular Tissues
}

\author{
Masashi Suzuki, George Seki*, Hideomi Yamada, Shoko Horita and Toshiro Fujita
}

Department of Internal Medicine, Faculty of Medicine, University of Tokyo, Japan

\begin{abstract}
Electrogenic $\mathrm{Na}^{+}-\mathrm{HCO}_{3}{ }^{-}$cotransporter $\mathrm{NBCe} 1$ is expressed in several tissues such as kidney, eye, and brain, where it may mediate distinct biological processes. In particular, NBCe1 in renal proximal tubules is essential for the regulation of systemic acid/base balance. On the other hand, NBCe1 in eye may be indispensable for the maintenance of tissue homeostasis. Consistent with this view, homozygous mutations in NBCel cause severe proximal renal tubular acidosis associated with ocular abnormalities such as band keratopathy, glaucoma, and cataract. The widespread expression of $\mathrm{NBCe} 1$ in eye suggests that the inactivation of $\mathrm{NBCe} 1$ per se may be responsible for the occurrence of these ocular abnormalities. In this review, we discuss about physiological and pathological roles of NBCe1 in eye.
\end{abstract}

Keywords: NBCe1, proximal renal tubular acidosis, band keratopathy, glaucoma, cataract.

\section{INTRODUCTION}

The presence of electrogenic $\mathrm{Na}^{+}-\mathrm{HCO}_{3}{ }^{-}$cotransporter NBCel was first demonstrated in 1983 by the electrophysiological experiment in isolated renal proximal tubules from salamander Ambystoma tigrinum [1]. In view of the large capacity of renal proximal tubules to absorb bicarbonate, NBCel was considered to play an important role in maintaining acid-base balance of extracellular fluid. Romero and colleagues first succeeded in NBCe1 cloning [2]. NBCe1 has two major spliced variants, the kidney type cotransporter NBCe1-A and the pancreas type cotransporter NBCe1-B as shown in Fig. (1). They originate from the same gene SLC4A4, and differ only at the N-terminus [3]. NBCe1A encodes 1035 amino acids and predicts a protein of 116 $\mathrm{kDa}$. NBCe1-B has unique N-terminal 85 amino acids replacing the first 41 amino acids of NBCe1-A. This NBCe1-B encodes 1079 amino acids and predicts a protein of $120 \mathrm{kDa}$. Another variant NBCe1-C (rb2NBC1) was also cloned from rat brain [4]. This variant has 61 unique Cterminal amino acids, the result of a 97-bp deletion and frame shift near the end of the open-reading. The encoded rat protein is 1094 amino acids and predicts a protein of about $130 \mathrm{kDa}$. This C-terminal NBCe1 variant has been also identified in human (GenBank accession number EF531618.1). However, the physiological significance of brain type variant remains to be clarified. The structure of NBCel is predicted based on the structure of anion exchanger AE1 [5]. NBCe1-B is widely expressed in several tissues such as pancreas [6,7], eye [8,9], colon [6] or brain $[4,6]$. While NBCe1-B may mediate bicarbonate secretion from pancreatic duct cells in pancreas [10], it may also mediate the maintenance of tissue homeostasis in the ocular tissues $[8,9]$. On the other hand, NBCe1-A is thought to

*Address correspondence to this author at the Department of Internal Medicine, Faculty of Medicine, University of Tokyo, 7-3-1 Hongo, Bunkyoku, Tokyo 113-0033, Japan; Tel: +81-3-3815-5411, Ext. 33004;

Fax:+81-3-5800-8806; E-mail: georgeseki-tky@umin.ac.jp represent a major pathway for basolateral bicarbonate exit from renal proximal tubules [10]. In support of this view, homozygous mutations in $\mathrm{NBCe} 1$ have been shown to cause severe proximal renal tubular acidosis (pRTA) associated with ocular abnormalities [11]. Because of the widespread expression of NBCe1 in several ocular tissues, the inactivation of $\mathrm{NBCe} 1$ seems to be directly responsible for ocular abnormalities [8]. Transport stoichiometry of NBCe1 seems to be either $1 \mathrm{Na}^{+}: 3 \mathrm{HCO}_{3}{ }^{-}$or $1 \mathrm{Na}^{+}: 2 \mathrm{HCO}_{3}{ }^{-}$[12-15]. Difference of the number of transported ions designates 'electrogenic'. While NBCe1-A favors the efflux transport mode from cells with $1 \mathrm{Na}^{+}: 3 \mathrm{HCO}_{3}{ }^{-}$stoichiometry in renal proximal tubules, NBCe1-B favors the influx transport mode into cells in corneal endothelium or pancreatic ducts with $1 \mathrm{Na}^{+}: 2 \mathrm{HCO}_{3}{ }^{-}$stoichiometry. However, the stoichiometry of NBCel can change depending on the cell type in which it is expressed or other factors such as intracellular $\mathrm{Ca}^{2+}$ concentrations [16-18].

\section{MUTATIONS OF NBCE1 AND PATHOGENESIS}

Igarashi and colleagues first identified that homozygous mutations in NBCe1 cause isolated severe pRTA and ocular abnormalities [11]. Up to now twelve cases of NBCe1 mutations have been reported [15,19-25]. They were eight missense mutations, two nonsense mutations, and two flameshift mutations. Most of these patients with homozygous NBCe1 mutations have severe metabolic acidosis (serum bicarbonate is usually less than $13 \mathrm{mEq} / \mathrm{l}$ ), stunted growth, and ocular abnormalities such as band keratopathy, glaucoma, and cataract. Some of them also presented with migraine as summarized in Table $\mathbf{1}$.

Several expression systems have been used to analyze the functional impacts of NBCel mutations. For example, Xenopus oocytes are used for the evaluation of the electrophysiologic properties of NBCe1 $[15,26]$. However, the surface expression in oocytes cannot predict the trafficking behaviors of $\mathrm{NBCe} 1$ in the polarized cells, and polarized Madin-Darby canine kidney (MDCK) cells seem to be more suitable for the evaluation of $\mathrm{NBCe} 1$ trafficking 


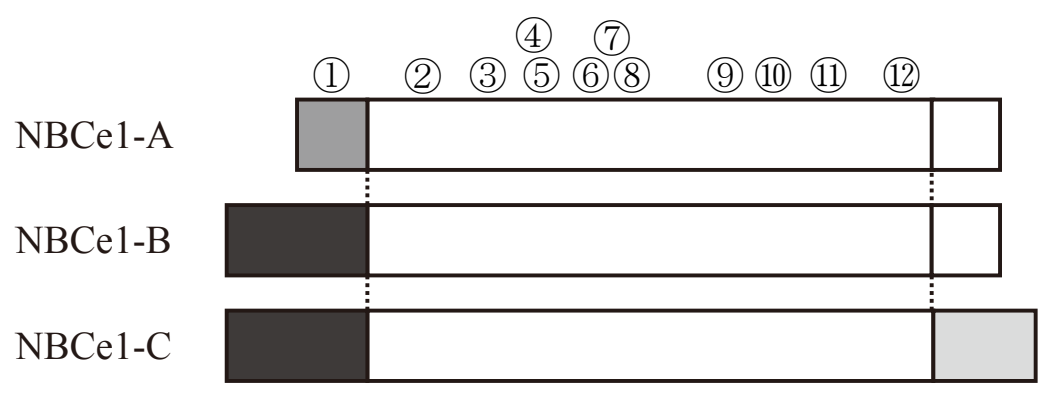

Fig. (1). Structures of NBCe1 variants and pRTA-related mutations. Different patterns in the squares indicate unique amino acids sequences. While NBCe1-A has a unique N-terminal, NBCe1-C has a unique C-terminal. Numbers in circles indicate pRTA-related NBCe1 mutations corresponding to Q29X (1), R298S (2), S427L (3), T485S (4), G486R (5), R510H (6), W516X (7), L522P (8), N721TxfsX29 (9), A799V (10), R881C (11), and S982NfsX4 (12). Q29X is an NBCe1-A specific mutation, leaving NBCe1-B and NBCe1-C intact. S982NfsX4 creates a flame-shift mutation in NBCe1-A and NBCe1-B, but may suppress the translation of NBCe1-C. The remaining mutations lie in the common region of $\mathrm{NBCe} 1$ variants.

abnormalities [21]. ECV304 and HEK293 cells are used for the evaluation of the transport activities of NBCe1 in mammalian cells [11,27]. C6 glioma cells, which retain several properties of astrocytes but lack the endogenous NBCe1 activity [28] are also used to evaluate the NBCe1 functions in astrocytes. Multiple experimental approaches to clarify the possible disease mechanism by NBCe1 mutations revealed that several mutations have loss of function (R298H, T485S, G486R and A799V). Other mutations show the trafficking abnormalities in mammalian cells (R298S, S427L, R510H, L522P, R881C and S982NfsX4). pRTA caused by NBCe1 mutations is always inherited by an autosomal recessive manner. However, we identified that the heterozygous NBCe1 S982NfsX4 mutation causes migraine and normal tension glaucoma without pRTA in an autosomal dominant manner. Although the S982NfsX4 mutant has the normal function as wild type in Xenopus oocytes, it shows trafficking defect that results in cytosolic retention in mammalian cells such as HEK293, C6 glioma and MDCK cells. Because S982NfsX4 and wild type NBCel form hetero-oligomer as reported [27], we speculated that the dominant negative effect by S982NfsX4 mutation might be responsible for migraine and glaucoma in the heterozygous family members [22].

\section{EXPRESSION AND PHYSIOLOGICAL ROLE OF NBCE1 IN EYE}

The expressions and physiological functions of NBCe1 have been demonstrated in several ocular tissues as shown in Fig. (2). For example, NBCe1 is thought to be expressed in the corneal endothelial cells. There is one study reporting the NBCel expression in rat corneal epithelial cells in addition to endothelial cells [9]. Bicarbonate flow out of cornea into aqueous humor is thought to be essential for the maintenance of corneal transparency [29]. Several reports suggested that NBCe1 is expressed only in the basolateral membrane of bovine and human corneal endothelial cells and to transport sodium and bicarbonate into aqueous humor [30-32]. Another group reported that $\mathrm{NBCe} 1$ is expressed in both bovine apical and basolateral membranes of endothelium [33]. On the other hand, NBCe1 specific siRNA knockdown in cultured bovine corneal endothelial cells decreased by $80-$ $90 \%$ expression of the cotransporter and significantly reduced basolateral $\mathrm{HCO}_{3}^{-}$permeability [34]. These data suggest that the basolateral NBCe1 may have a more important role in the corneal endothelium. Partial knockdown of $\mathrm{NBCe} 1$ in vivo in rabbit failed to affect the corneal thickness, however 25\% NBCe1 knockdown induced

Table 1. Phenotypes and Functional Properties of NBCe1 Mutations

\begin{tabular}{|c|c|c|c|c|c|c|c|c|c|c|c|c|}
\hline & R298S & Q29X & S427L & T485S & G486R & R510H & W516X & L522P & N721TxfsX29 & A799V & R881C & S982NfsX4 \\
\hline Gender & $\mathrm{F}$ & $\mathrm{F}$ & $\mathrm{F}$ & $\mathrm{M}$ & $\mathrm{F}$ & $\mathrm{F}$ & $\mathrm{F}$ & M & $\mathrm{M}$ & $\mathrm{F}$ & $\mathrm{F}$ & $\mathrm{F}$ \\
\hline Number of patients & 1 & 1 & 1 & 1 & 1 & 1 & 1 & 1 & 1 & 1 & 1 & 2 \\
\hline Country & Japan & Japan & USA & USA & Brazil & Japan & Taiwan & USA & USA & Turkey & UAE & Belgium \\
\hline $\begin{array}{l}\text { Blood } \mathrm{HCO}_{3}^{-}(\mathrm{mEq} / \mathrm{l}) \\
\text { (normal value: } 24)\end{array}$ & 8 & 9.4 & 11 & 13 & 3 & 5.5 & 10 & NA & 13.2 & 6.3 & 10.6 & $14.8 / 17.3$ \\
\hline Band keratopathy & + & - & + & + & + & + & + & + & + & + & + & + \\
\hline Glaucoma & + & + & + & - & - & + & + & + & + & + & + & + \\
\hline Cataract & + & - & + & + & + & + & + & + & + & + & + & + \\
\hline Migraine & - & - & NA & - & - & + & - & + & + & - & + & + \\
\hline $\begin{array}{l}\text { Proper membrane expression } \\
\text { in mammalian cells }\end{array}$ & - & - & - & + & + & - & - & - & - & + & - & - \\
\hline Activity in HEK 293 cells & $39 \%$ & NA & NA & $30 \%$ & $42 \%$ & $6 \%$ & NA & $0 \%$ & NA & $32 \%$ & $4 \%$ & $3 \%$ \\
\hline
\end{tabular}


higher corneal swelling relative to control eyes [35]. By contrast, near-complete inactivation of $\mathrm{NBCe} 1$ in vivo caused corneal edema and opacity [25], consistent with the essential role of $\mathrm{NBCe} 1$ in the maintenance of corneal transparency.

The expression of NBCe1 was found in both apical and basolateral membranes in lens epithelium of human and rat $[8,9]$. In the human lens epithelium cell lines, HLE cells, the transport activity of sodium bicarbonate cotransport was detected. Because this activity was largely suppressed by the specific hammerhead ribozyme against $\mathrm{NBCe} 1$, it might reflect the NBCe1 activity [8]. The lens is a tissue without vascular supply, and simple diffusion of nutrients may be insufficient to support its metabolic consumption [36]. One study indeed reported that the cultured lens epithelium can actively transport fluid from the anterior to the posterior side against a hydrostatic pressure [37]. Although the functions and importance of NBCe1 in lens epithelium still remain unclear, the vectorial transport by $\mathrm{NBCe} 1$ might contribute to the transparency and hydration of lens similarly as in cornea.

Some studies identified the sodium bicarbonate cotransport activity that may originate from $\mathrm{NBCe} 1$ in the apical membrane of pigmented epithelium in frog, rat and frog retina [9,38-40]. NBCel in the apical membrane of pigmented epithelium may transport sodium and bicarbonate from sub-retinal space into the pigmented epithelium. The expression of NBCe1 in Müller cells was also detected, which might regulate local $\mathrm{pH}$ within retina $[9,41]$.

NBCe1 was also found in human and rat pigmented and nonpigmented ciliary epithelium and in porcine nonpigmented ciliary epithelium $[8,9,42]$. In these epithelia, the functional evidence for anion exchanger has been suggested [43,44]. However, Shahidullah and colleagues reported that the production of aqueous humor was reduced by 4,4 '-diisothiocyanatostilbene-2,2'-disulfonic acid and a carbonic anhydrase inhibitor acetazolamide in a low chloride buffer, suggesting that NBCe1 might be also involved in influx and efflux of bicarbonate into/from pigmented ciliary epithelium [42].

The presence of electrogenic sodium bicarbonate cotransporter activity in human trabecular meshwork cells was demonstrated by an electro-physiological experiment [45]. The immunohistochemical analysis also detected NBCe1 in human trabecular meshwork [8], suggesting that NBCe1 has some roles in trabecular meshwork cells.

The expression of NBCe1 was reported in other ocular tissues such as rat conjunctival epithelium and endothelium of human choriocapillaris $[8,9,46]$. However, the physiological significance of NBCe1 in these tissues remains unclear.

The immunohistochemical analysis and RT-PCR revealed the expression of NBCe1-A and NBCe1-B in human and rat cornea endothelium, human trabecular meshwork, rat lens epithelium, HLE cells, rat ciliary body and basal cells of rat conjunctiva [8,9,47]. However, the signals of NBCe1-A in RT-PCR were weaker than those of NBCe1-B, suggesting that NBCe1-B may be the main variant expressed in eye.

\section{MUTATIONS OF NBCE1 AND OCULAR ABNORMALITIES}

All the pRTA-related homozygous NBCe1 mutations except the NBCe1-A specific mutation Q29X cause band keratopathy. The inactivation of $\mathrm{NBCe} 1$ in corneal endothelium may reduce bicarbonate efflux from stroma into aqueous humor and increase bicarbonate concentrations in stroma. As shown in Fig. (3), the resultant increase in local $\mathrm{pH}$ may facilitate calcium deposition, resulting in band keratopathy. Sometimes EDTA chelation was tried for the treatment of this condition [24]. Histopathological observations of the cornea of band keratopathy associated with NBCe1 mutation have not been reported. A report analyzing band keratopathy associated with juvenile

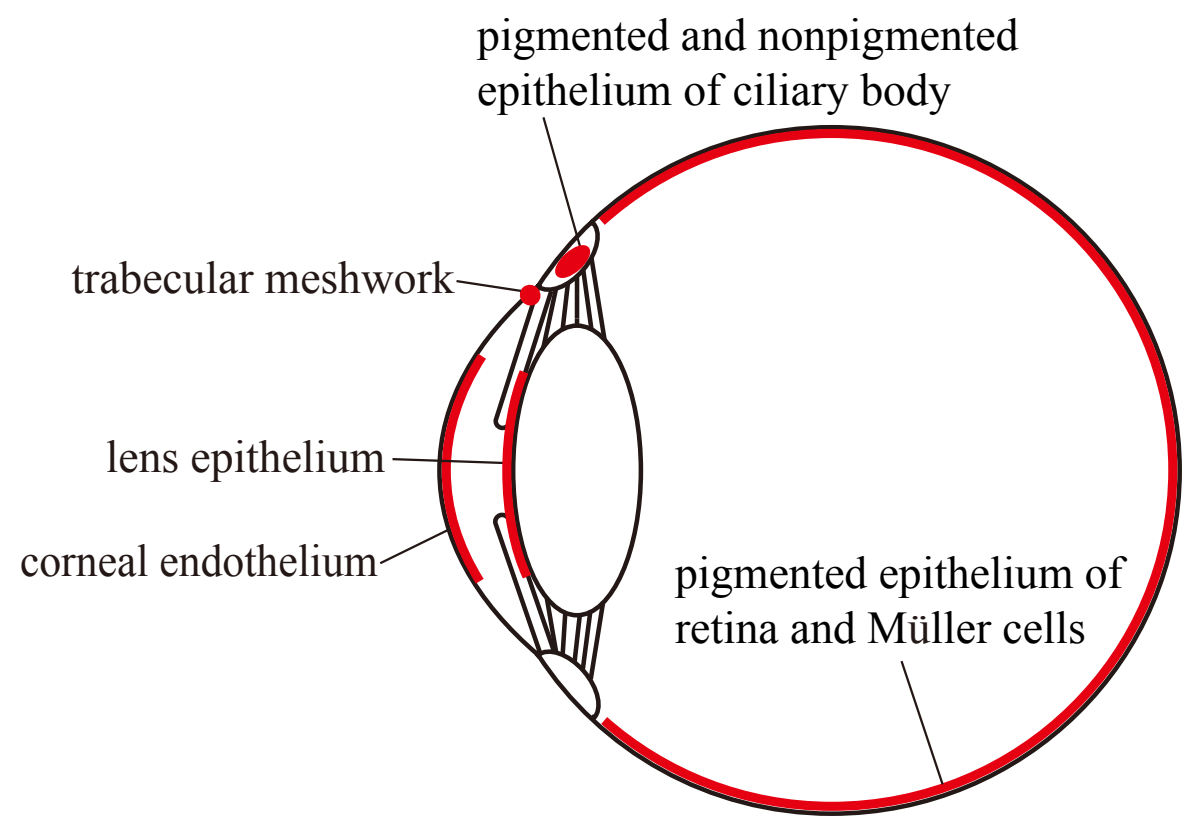

Fig. (2). Major sites of NBCe1 expression in eye. 


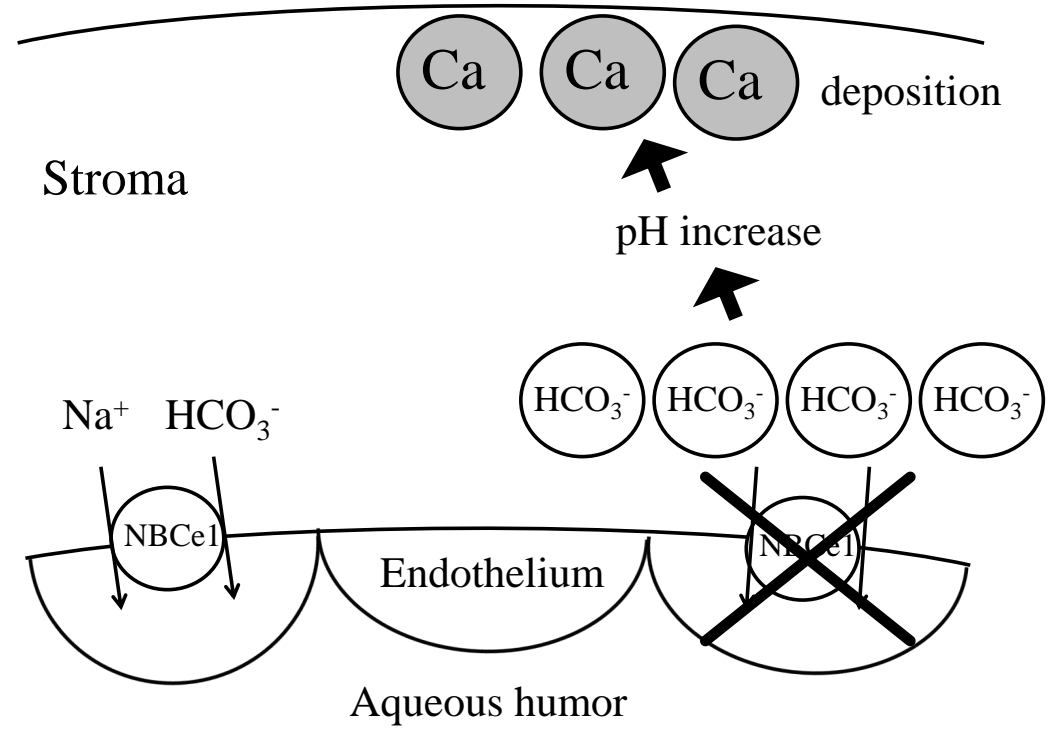

Fig. (3). Proposed mechanism of band keratopathy by NBCe1 mutations. Inactivation of NBCe1 may increase the concentration of bicarbonate in corneal stroma, which may facilitate the calcium deposition.

rheumatoid arthritis shows that precipitated calcium depositions are observed in Bowman's layer or superficial lamellae of stroma [48].

Cataract was also found in all the homozygous mutations except Q29X. Although the importance of bicarbonate transport in lens epithelium remains to be established, NBCe1 might contribute to the transparency of lens.

Ten of twelve NBCe1 mutations developed glaucoma. Interestingly, Q29X also causes glaucoma, indicating that not only NBCe1-B but also NBCe1-A has an important physiological role in the pathogenesis of glaucoma. Although the heterozygous S982NfsX4 mutation developed normal tension glaucoma, the homozygous NBCe1 mutations usually developed open angle glaucoma with elevated intraocular pressure [22]. Glaucoma is the optic neuropathy characterized by death of a substantial number of retinal ganglion cells in the inner retina and loss of the optic nerve axons [49]. The definite mechanisms of glaucoma induced by NBCe1 mutations remain speculative. However, glaucoma is often associated with elevated intraocular pressure, and trabecular meshwork determines resistance of aqueous humor outflow [50]. Indeed, the contraction of trabecular meshwork cells is known to increase the outflow resistance and elevate intraocular pressure [51]. On the other hand, the contraction of trabecular meshwork cells is influenced by voltage-dependent L-type $\mathrm{Ca}^{2+}$ channels [52]. Therefore, the inactivation of electrogenic transporter NBCe1 may affect the contraction of trabecular meshwork cells by modifying the membrane potentials and intracellular $\mathrm{Ca}^{2+}$ concentration [8].

On the other hand, dysfunctional local $\mathrm{pH}$ regulation in the retina may be involved especially in the occurrence of normal-tension glaucoma by the heterozygous S982NfsX4 mutation. Indeed, retinal excitation by light is known to induce an increase in extracellular $\mathrm{pH}$ resulting in a gain of synaptic activity [53,54], and NBCe1 in retinal Müller cells may counteract this light-induced extracellular alkalosis $[9,41]$. Consistent with this speculation, the glutamate excitotoxicity was reported to facilitate the degeneration of retinal ganglion cells [55]. Interestingly, the association between normal-tension glaucoma and migraine has been reported [56]. Future studies will be required whether heterozygous NBCe1 mutations without pRTA may represent a risk factor for migraine and glaucoma.

Kao and colleagues recently reported that electrogenic sodium bicarbonate cotransporter 2, NBCe2 knockout in mouse caused loss of photoreceptors, ganglion cells and retinal detachment [57]. $\mathrm{NBCe} 2$ is expressed in whole body such as brain, heart, kidney, and muscle and considered to play important role in producing cerebrospinal fluid in choroid plexus [57-59]. Although functions of $\mathrm{NBCe} 2$ in retina remain unclear, it might also play an important role in maintaining retinal homeostasis.

\section{ACKNOWLEDGEMENTS}

This study was supported in part by grants from the Ministry of Education, Culture, Sports, Science and Technology of Japan.

\section{CONFLICT OF INTEREST}

Declared none.

\section{REFERENCES}

[1] Boron WF, Boulpaep EL. Intracellular $\mathrm{pH}$ regulation in the renal proximal tubule of the salamander. Basolateral $\mathrm{HCO}_{3}{ }^{-}$transport. J Gen Physiol 1983; 81: 53-94.

[2] Romero MF, Hediger MA, Boulpaep EL, Boron WF. Expression cloning and characterization of a renal electrogenic $\mathrm{Na}^{+} / \mathrm{HCO}_{3}{ }^{-}$ cotransporter. Nature 1997; 387: 409-13.

[3] Abuladze N, Song M, Pushkin A, et al. Structural organization of the human $\mathrm{NBCl}$ gene: $\mathrm{kNBCl}$ is transcribed from an alternative promoter in intron 3. Gene 2000; 251: 109-22.

[4] Bevensee M, Schmitt B, Choi I, Romero M, Boron WF. An electrogenic $\mathrm{Na}^{+}-\mathrm{HCO}_{3}^{-}$cotransporter (NBC) with a novel $\mathrm{COOH}-$ terminus, cloned from rat brain. Am J Physiol Cell Physiol 2000; 278: C1200-11.

[5] Boron WF. Acid-base transport by the renal proximal tubule. J Am Soc Nephrol 2006; 17: 2368-82.

[6] Abuladze N, Lee I, Newman D, et al. Molecular cloning, chromosomal localization, tissue distribution, and functional 
expression of the human pancreatic sodium bicarbonate cotransporter. J Biol Chem 1998; 273: 17689-95.

[7] Satoh $\mathrm{H}$, Moriyama $\mathrm{N}$, Hara $\mathrm{C}$, et al. Localization of $\mathrm{Na}^{+}-\mathrm{HCO}_{3}{ }^{-}$ cotransporter (NBC-1) variants in rat and human pancreas. Am J Physiol Cell Physiol 2003; 284: C729-37.

[8] Usui T, Hara M, Satoh $\mathrm{H}$, et al. Molecular basis of ocular abnormalities associated with proximal renal tubular acidosis. J Clin Invest 2001; 108: 107-15.

[9] Bok D, Schibler MJ, Pushkin A, et al. Immunolocalization of electrogenic sodium-bicarbonate cotransporters $\mathrm{pNBC1}$ and kNBC1 in the rat eye. Am J Physiol Renal Physiol 2001; 281: F920-35.

[10] Shumaker H, Amlal H, Frizzell R, Ulrich C, Soleimani M. CFTR drives $\mathrm{Na}^{+}-\mathrm{nHCO}_{3}{ }^{-}$cotransport in pancreatic duct cells: a basis for defective $\mathrm{HCO}_{3}^{-}$secretion in CF. Am J Physiol Cell Physiol 1999; 276: $\mathrm{C} 16-25$.

[11] Igarashi T, Inatomi J, Sekine T, et al. Mutations in SLC4A4 cause permanent isolated proximal renal tubular acidosis with ocular abnormalities. Nat Genet 1999; 23: 264-6.

[12] Soleimani M, Grassi SM, Aronson PS. Stoichiometry of $\mathrm{Na}^{+}-$ $\mathrm{HCO}_{3}{ }^{-}$cotransport in basolateral membrane vesicles isolated from rabbit renal cortex. J Clin Invest 1987; 79: 1276-80.

[13] Seki G, Coppola S, Yoshitomi K, et al. On the mechanism of bicarbonate exit from renal proximal tubular cells. Kidney Int 1996; 49: 1671-7.

[14] Yoshitomi K, Burckhardt BC, Frömter E. Rheogenic sodiumbicarbonate cotransport in the peritubular cell membrane of rat renal proximal tubule. Pflugers Arch 1985; 405: 360-6.

[15] Horita S, Yamada H, Inatomi J, et al. Functional analysis of NBC1 mutants associated with proximal renal tubular acidosis and ocular abnormalities. J Am Soc Nephrol 2005; 16: 2270-8.

[16] Gross E, Hawkins K, Abuladze N, et al. The stoichiometry of the electrogenic sodium bicarbonate cotransporter NBC1 is cell-type dependent. J Physiol 2001; 531: 597-603.

[17] Bonanno JA. Molecular mechanisms underlying the corneal endothelial pump. Exp Eye Res 2012; 95: 2-7.

[18] Seki G, Yamada H, Horita S, et al. Physiological and pathophysiological roles of the electrogenic $\mathrm{Na}^{+}-\mathrm{HCO}_{3}{ }^{-}$ cotransporter NBCe1. Open J Mol Integr Physiol 2011; 1: 9-16.

[19] Igarashi T, Inatomi J, Sekine T, et al. Novel nonsense mutation in the $\mathrm{Na}^{+} / \mathrm{HCO}_{3}{ }^{-}$cotransporter gene (SLC4A4) in a patient with permanent isolated proximal renal tubular acidosis and bilateral glaucoma. J Am Soc Nephrol 2001; 12: 713-8.

[20] Inatomi J, Horita S, Braverman N, et al. Mutational and functional analysis of SLC4A4 in a patient with proximal renal tubular acidosis. Pflugers Arch 2004; 448: 438-44.

[21] Suzuki M, Vaisbich MH, Yamada $H$, et al. Functional analysis of a novel missense NBC1 mutation and of other mutations causing proximal renal tubular acidosis. Pflugers Arch 2008; 455: 583-93.

[22] Suzuki M, Van Paesschen W, Stalmans I, et al. Defective membrane expression of the $\mathrm{Na}^{+}-\mathrm{HCO}_{3}{ }^{-}$cotransporter $\mathrm{NBCe} 1$ is associated with familial migraine. Proc Natl Acad Sci USA 2010; 107: $15963-8$

[23] Dinour D, Chang MH, Satoh J, et al. A novel missense mutation in the sodium bicarbonate cotransporter (NBCe1/SLC4A4) causes proximal tubular acidosis and glaucoma through ion transport defects. J Biol Chem 2004; 279: 52238-46.

[24] Demirci FYK, Chang MH, Mah TS, Romero MF, Gorin MB. Proximal renal tubular acidosis and ocular pathology: a novel missense mutation in the gene (SLC4A4) for sodium bicarbonate cotransporter protein (NBCe1). Mol Vis 2006; 12: 324-30.

[25] Lo YF, Yang SS, Seki G, et al. Severe metabolic acidosis causes early lethality in NBC1 W516X knock-in mice as a model of human isolated proximal renal tubular acidosis. Kidney Int 2011; 79: 730-41.

[26] Romero MF, Boron WF. Electrogenic $\mathrm{Na}^{+} / \mathrm{HCO}_{3}{ }^{-}$cotransporters: cloning and physiology. Annu Rev Physiol 1999; 61: 699-723.

[27] Kao L, Sassani P, Azimov R, et al. Oligomeric structure and minimal functional unit of the electrogenic sodium bicarbonate cotransporter NBCe1-A. J Biol Chem 2008; 283: 26782-94.

[28] Shrode LD, Putnam RW. Intracellular $\mathrm{pH}$ regulation in primary rat astrocytes and C6 glioma cells. Glia 1994; 12: 196-210.

[29] Hodson S, Miller F. The bicarbonate ion pump in the endothelium which regulates the hydration of rabbit cornea. J Physiol 1976; 263 : 563-77.
[30] Bonanno JA, Guan Y, Jelamskii S, Kang XJ. Apical and basolateral $\mathrm{CO}_{2}-\mathrm{HCO}_{3}^{-}$permeability in cultured bovine corneal endothelial cells. Am J Physiol 1999; 277: C545-53.

[31] Sun XC, Bonanno JA, Jelamskii S, Xie Q. Expression and localization of $\mathrm{Na}^{+}-\mathrm{HCO}_{3}^{-}$cotransporter in bovine corneal endothelium. Am J Physiol Cell Physiol 2000; 279: C1648-55.

[32] Sun XC, Bonanno JA. Identification and cloning of the $\mathrm{Na} / \mathrm{HCO}_{3}$ cotransporter (NBC) in human corneal endothelium. Exp Eye Res 2003; 77: 287-95.

[33] Diecke F, Wen Q, Sanchez J, Kuang K, Fischbarg J. Immunocytochemical localization of $\mathrm{Na}^{+}-\mathrm{HCO}_{3}{ }^{-}$cotransporters and carbonic anhydrase dependence of fluid transport in corneal endothelial cells. Am J Physiol Cell Physiol 2004; 286: C1434-42.

[34] Li J, Sun XC, Bonanno JA. Role of NBC1 in apical and basolateral $\mathrm{HCO}_{3}^{-}$permeabilities and transendothelial $\mathrm{HCO}_{3}^{-}$fluxes in bovine corneal endothelium. Am J Physiol Cell Physiol 2005; 288: C73946.

[35] Liu CL, Cheng QA, Nguyen T, Bonanno JA. Knockdown of NBCel in vivo compromises the corneal endothelial pump. Invest Ophthalmol Vis Sci 2010; 51: 5190-7.

[36] Harris JE, Hauschildt JD, Nordquist LT. Transport of glucose across the lens surfaces. Am J Ophthalmol 1955; 39: 161-9.

[37] Fischbarg J, Diecke FP, Kuang K, et al. Transport of fluid by lens epithelium. Am J Physiol 1999; 276: C548-57.

[38] Hughes BA, Adorante JS, Miller SS, Lin H. Apical electrogenic $\mathrm{NaHCO}_{3}$ cotransport. A mechanism for $\mathrm{HCO}_{3}$ absorption across the retinal pigment epithelium. J Gen Physiol 1989; 94: 125-50.

[39] Lin H, Miller SS. pHi regulation in frog retinal pigment epithelium: two apical membrane mechanisms. Am J Physiol 1991; 261: C13242.

[40] Lin H, Kenyon E, Miller SS. Na-dependent pHi regulatory mechanisms in native human retinal pigment epithelium. Invest Ophthalmol Vis Sci 1992; 33: 3528-38.

[41] Newman EA. Sodium-bicarbonate cotransport in retinal astrocytes and Müller cells of the rat. Glia 1999; 26: 302-8.

[42] Shahidullah M, To CH, Pelis RM, Delamere NA. Studies on bicarbonate transporters and carbonic anhydrase in porcine nonpigmented ciliary epithelium. Invest Ophthalmol Vis Sci 2009; 50: $1791-800$

[43] McLaughlin CW, Peart D, Purves RD, Carre DA, Macknight AD, Civan MM. Effects of $\mathrm{HCO}_{3}{ }^{-}$on cell composition of rabbit ciliary epithelium: a new model for aqueous humor secretion. Invest Ophthalmol Vis Sci 1998; 39: 1631-41.

[44] Counillon L, Touret $\mathrm{N}$, Bidet $\mathrm{M}$, et al. $\mathrm{Na}^{+} / \mathrm{H}^{+}$and $\mathrm{CI}^{-} / \mathrm{HCO}_{3}$ antiporters of bovine pigmented ciliary epithelial cells. Pflugers Arch 2000; 440: 667-78.

[45] Lepple-Wienhues A, Rauch R, Clark AF, Grássmann A, Berweck S, Wiederholt M. Electrophysiological properties of cultured human trabecular meshwork cells. Exp Eye Res 1994; 59: 305-11.

[46] Yang Z, Alvarez BV, Chakarova C, et al. Mutant carbonic anhydrase 4 impairs $\mathrm{pH}$ regulation and causes retinal photoreceptor degeneration. Hum Mol Genet 2005; 14: 255-65.

[47] Usui T, Seki G, Amano S, et al. Functional and molecular evidence for $\mathrm{Na}^{+}-\mathrm{HCO}_{3}^{-}$cotransporter in human corneal endothelial cells. Pflugers Arch 1999; 438: 458-62.

[48] O'Connor GR. Calcific band keratopathy. Trans Am Ophthalmol Soc 1972; 70: 58-81.

[49] Quigley HA. Glaucoma. Lancet 2011; 377: 1367-77.

[50] Wiederholt M, Thieme H, Stumpff F. The regulation of trabecular meshwork and ciliary muscle contractility. Prog Retin Eye Res 2000; 19: 271-95.

[51] Wiederholt M, Bielka S, Schweig F, Lütjen-Drecoll E, LeppleWienhues A. Regulation of outflow rate and resistance in the perfused anterior segment of the bovine eye. Exp Eye Res 1995; 61: 223-34.

[52] Steinhausen K, Stumpff F, Strauss O, Thieme H, Wiederholt M. Influence of muscarinic agonists and tyrosine kinase inhibitors on L-type $\mathrm{Ca}^{2+}$ channels in human and bovine trabecular meshwork cells. Exp Eye Res 2000; 70: 285-93.

[53] Borgula GA, Karwoski CJ, Steinberg RH. Light-evoked changes in extracellular $\mathrm{pH}$ in frog retina. Vision Res 1989; 29: 1069-77.

[54] Barnes S, Merchant V, Mahmud F. Modulation of transmission gain by protons at the photoreceptor output synapse. Proc Natl Acad Sci USA 1993; 90: 10081-5.

[55] Hare W, WoldeMussie E, Lai R, et al. Efficacy and safety of memantine, an NMDA-Type open-channel blocker, for reduction 
of retinal injury associated with experimental glaucoma in rat and monkey. Surv Ophthalmol 2001; 45: S284-9.

[56] Cursiefen C, Wisse M, Cursiefen S, Jünemann A, Martus P, Korth $\mathrm{M}$. Migraine and tension headache in high-pressure and normalpressure glaucoma. Am J Ophthalmol 2000; 129: 102-4.

[57] Kao L, Kurtz LM, Shao X, et al. Severe neurologic impairment in mice with targeted disruption of the electrogenic sodium bicarbonate cotransporter NBCe2 (Slc4a5). J Biol Chem 2011; 286: 32563-74.
[58] Sassani P, Pushkin A, Gross E, et al. Functional characterization of NBC4: a new electrogenic sodium-bicarbonate cotransporter. Am J Physiol Cell Physiol 2002; 282: C408-16.

[59] Bouzinova EV, Praetorius J, Virkki LV, Nielsen S, Boron WF, Aalkjaer C. $\mathrm{Na}^{+}$-dependent $\mathrm{HCO}_{3}{ }^{-}$uptake into the rat choroid plexus epithelium is partially DIDS sensitive. Am J Physiol Cell Physiol 2005; 289: C1448-56.

Received: April 15, 2012

(C) Suzuki et al.; Licensee Bentham Open.

This is an open access article licensed under the terms of the Creative Commons Attribution Non-Commercial License (http://creativecommons.org/licenses/by$\mathrm{nc} / 3.0 /$ ) which permits unrestricted, non-commercial use, distribution and reproduction in any medium, provided the work is properly cited. 